Original Research Article

\title{
An evaluation of knowledge, attitude and practice of pharmacovigilance among medical students and doctors at a tertiary care hospital
}

\author{
Ravindra S. Beedimani ${ }^{1}$, Sameer Uz Zaman ${ }^{1 *}$, Subrahmanyam Darbha ${ }^{2}$, \\ Sharat Chandra Potturi ${ }^{1}$
}

${ }^{1}$ Department of Pharmacology, ${ }^{2}$ Department of Community Medicine, Kamineni Academy of Medical Sciences and Research Centre (KAMSRC), L.B. Nagar, Hyderabad, Telangana, India

Received: 13 December 2017 Accepted: 04 January 2018

\section{*Correspondence to:}

Dr. Sameer Uz Zaman, Email: samsparkin@gmail.com

Copyright: (C) the author(s), publisher and licensee Medip Academy. This is an openaccess article distributed under the terms of the Creative Commons Attribution NonCommercial License, which permits unrestricted noncommercial use, distribution, and reproduction in any medium, provided the original work is properly cited.

\begin{abstract}
Background: Drugs are one of the most commonly used interventions in medical therapeutics. Spontaneous reporting of adverse drug reactions (ADRs) is the backbone of pharmacovigilance (PV) program. Under-reporting of ADRs by prescribers was possibly due to lack of knowledge, attitude and practices regarding PV. This study was done to assess the knowledge, attitude, and practice (KAP) of medical students (grouped to sixth and eighth semester) and medical doctors about PV in a tertiary care hospital.

Methods: It was a questionnaire based cross-sectional study administered to 246 medical students and doctors. Study tool was a validated questionnaire containing 15 questions to evaluate KAP of PV among medical students and doctors. A descriptive analysis of data was done where necessary, statistical significance for associations between the group and their responses to questionnaire was provided using Pearson Chi square test and Fisher exact test.

Results: Sixty-eight percent of the participants (90\% doctors; $76 \%$ eighthsemester and $46 \%$ sixth-semester medical students) know the correct definition of PV. Sixty-one percent of the participants $(67 \%$ sixth-semester, $61 \%$ doctors and $53 \%$ eighth-semester) think that reporting is a professional obligation for them. Only $15 \%$ of the participants have ever been taught or trained on how to report an ADR.

Conclusions: Medical doctors and students lack adequate knowledge and practice of reporting ADRs, but they seem to have a positive attitude towards the PV program. Our study findings strongly suggest that there is a great need to create awareness amongst them to promote reporting of ADRs.
\end{abstract}

Keywords: Adverse drug reactions, Doctors, Medical students, Pharmacovigilance

\section{INTRODUCTION}

Adverse drug reactions (ADRs) are an important cause of morbidity and mortality. ${ }^{1}$ ADRs are recognized as one of the major concerns associated with drug therapy. According to the World Health Organization (WHO), an ADR is "any noxious, unintended and undesired effect of a drug which occurs at doses used in humans for prophylaxis, diagnosis or therapy of disease, or for the modification of physiologic function". WHO estimates that more than half of all medicines are prescribed, dispensed or sold inappropriately, and half of all patients fail to take them correctly. The overuse, underuse or misuse of medicines results in wastage of scarce resources and health hazards. ${ }^{2}$

Pharmacovigilance (PV) is defined as "the science and activities relating to the detection, assessment, understanding and prevention of adverse effects or any other possible drug-related problem, particularly long term and short term adverse effects of medicines". Gross underreporting of ADRs is a cause of concern, the reason for which may be inadequate funds, lack of trained staff and lack of awareness about detection, communication and 
spontaneous monitoring of ADRs. ${ }^{3}$ The success of a PV program depends upon active involvement of the healthcare professionals (HCPs) like doctors, pharmacists, and nurses in activities to strengthen the PV programs.

ADRs can be divided into two major groups related to hospital admission. One group of ADRs lead to hospital admission and the other group of ADRs occur in inpatients of other illness. It has been reported that the total incidence of both groups of ADRs was $6.7 \%$ with an overall fatality rate of $0.32 \%$; of which the incidence of ADRs responsible for hospital admission was $4.7 \%$ and $2.0 \%$ occurred in in-patients. ${ }^{4,5}$ ADRs are ranked between the fourth and sixth as leading causes of death in the USA. ${ }^{[5]}$ ADRs are reported to be the seventh most common cause of death in Sweden. ${ }^{6}$

The Uppsala Monitoring centre (UMC, WHO), Sweden has the international database of ADR report data of different countries. It is estimated that fewer than $10 \%$ of all ADRs are reported worldwide. ${ }^{7}$ In the year 2013, India's contribution to WHO-UMC's global drug safety database (Vigibase) was $2 \% .^{8}$ India is one of the countries whose contribution to UMC database is still not significant. The ADR reporting rate in India is below 1\% compared to the worldwide rate of $5 \% .{ }^{9}$ We do not have a vibrant ADR monitoring culture among HCPs in India. It is important to improve the knowledge, attitude, and practice (KAP) of HCPs regarding ADRs to enhance reporting. This study was planned with the objective to evaluate the KAP towards PV and ADR reporting in medical doctors and students of a tertiary care hospital in India.

\section{METHODS}

Institutional ethics committee approval was obtained for conducting the study. This was a cross-sectional, questionnaire-based study conducted at general hospital and medical institution. The study instrument was a multiple-choice questionnaire developed, modified and peers reviewed by the teaching faculties of the department of pharmacology in a medical college based on previous studies. ${ }^{10-12}$ The finalized KAP questionnaire consisted of 15 questions (Q): encompassing knowledge (Q.1-7); attitude (Q.8-12); and practice aspects (Q.13-15) of PV and ADR reporting (Annexure 1). It was administered to 246 participants (62 medical doctors; 95 sixth-semester; 89 eighth-semester medical students). Questions 1 through 7, Q 9 and Q10 were evaluated for correct response. Multiple responses were possible for Q 8. Questions 11 through 15 were evaluated for attitude and practices of PV.

\section{Study population}

Sixty-two medical doctors including faculty members from both the basic and clinical sciences departments of Medical College and General Hospital were part of the study. In addition, 88 eighth-semester and 96 sixthsemester medical students of the Medical College were included in the study. The study participants were instructed not to write their names on the questionnaire to avoid any potential bias.

Informed consent was obtained from all the participants and they were briefed about the objectives of the study. Questionnaires were administered to the faculty members in their respective departments; and lecture halls were used for medical students. Approximately thirty-minutes was allowed for completion of the questionnaire.

\section{Statistical analysis}

Statistical analysis software STATA v.11.2 (Stata Corp LLC, College Station, Texas, USA) was used for data management and analysis. Descriptive statistics were provided for age and gender distribution of participants. Evaluation summary tables were provided for each question, and statistical significance for association between groups (sixth-semester, eighth semester and medical doctors) and their response to each question was reported using Pearson Chi square and Fisher exact test.

\section{RESULTS}

Of the 246 study participants (Table 1), 135 (55\%) were in the age group $20-25$ years. Sixty two $(25 \%)$ participants did not mention their age.

Table 1: Age distribution of the study participants.

\begin{tabular}{|ll|}
\hline \multicolumn{2}{|l|}{ Age distribution of study participants } \\
\hline Age group & $\mathbf{N}(\boldsymbol{\%})$ \\
\hline $20-25$ & $135(54.88)$ \\
\hline $26-30$ & $7(2.85)$ \\
\hline $31-35$ & $18(7.32)$ \\
\hline $36-40$ & $10(4.07)$ \\
\hline $41-45$ & $5(2.03)$ \\
\hline $46-50$ & $3(1.22)$ \\
\hline $56-60$ & $2(0.81)$ \\
\hline $61-65$ & $4(1.63)$ \\
\hline Not mentioned & $62(25.2)$ \\
\hline Total & $246(100)$ \\
\hline
\end{tabular}

$\mathrm{N}=$ number of participants

Table 2: Gender distribution of study participants.

\begin{tabular}{|c|c|c|c|c|}
\hline Sex & $\begin{array}{l}\mathbf{6}^{\text {th }} \\
\text { semester } \\
\mathbf{N}=95 \\
(\%)\end{array}$ & $\begin{array}{l}\mathbf{8}^{\text {th }} \\
\text { semester } \\
\mathbf{N}=\mathbf{8 9} \\
(\%)\end{array}$ & $\begin{array}{l}\text { Medical } \\
\text { doctor } \\
\mathrm{N}=62 \\
(\%)\end{array}$ & $\begin{array}{l}\text { Total } \\
N=246 \\
(\%)\end{array}$ \\
\hline Female & $\begin{array}{l}46 \\
(48.42)\end{array}$ & $\begin{array}{l}63 \\
(70.79)\end{array}$ & $\begin{array}{l}24 \\
(38.71)\end{array}$ & $\begin{array}{l}133 \\
(54.01)\end{array}$ \\
\hline Male & $\begin{array}{l}23 \\
(24.21)\end{array}$ & $\begin{array}{l}15 \\
(16.85)\end{array}$ & $\begin{array}{l}27 \\
(43.55)\end{array}$ & $\begin{array}{l}65 \\
(26.42)\end{array}$ \\
\hline $\begin{array}{l}\text { Not } \\
\text { mentioned }\end{array}$ & $\begin{array}{l}26 \\
(27.37)\end{array}$ & $11(12.36)$ & $\begin{array}{l}11 \\
(17.74)\end{array}$ & $\begin{array}{l}48 \\
(19.51)\end{array}$ \\
\hline
\end{tabular}

$\mathrm{N}=$ number of study participants 
Table 3: Response of medical students and doctors to questions related to knowledge of pharmacovigilance.

\begin{tabular}{|c|c|c|c|c|c|c|c|}
\hline \multirow{2}{*}{ Q. No } & \multirow{2}{*}{ Response } & \multirow{2}{*}{$\begin{array}{l}\text { 6th semester } \\
N=95\end{array}$} & \multirow{2}{*}{$\begin{array}{l}\text { 8th semester } \\
\mathbf{N}=\mathbf{8 9}\end{array}$} & \multirow{2}{*}{$\begin{array}{l}\text { Doctors } \\
N=62\end{array}$} & \multirow{2}{*}{$\begin{array}{l}\text { Total } \\
\mathrm{N}=\mathbf{2 4 6}\end{array}$} & \multicolumn{2}{|c|}{ Statistical significance p-value } \\
\hline & & & & & & Pearson $\chi^{2}$ test & Fisher Exact test \\
\hline Q 1 & Correct $(\%)$ & $\begin{array}{l}44 \\
(46.32)\end{array}$ & $\begin{array}{l}68 \\
(76.4)\end{array}$ & $\begin{array}{l}55 \\
(90.16)\end{array}$ & $\begin{array}{l}167 \\
(68.16)\end{array}$ & $\begin{array}{l}2 \mathrm{df} .=37.28 \\
\mathrm{p}<0.001^{* *}\end{array}$ & $\mathrm{p}=0.0001 * *$ \\
\hline Q 2 & Correct $(\%)$ & $\begin{array}{l}94 \\
(98.95)\end{array}$ & $\begin{array}{l}83 \\
(93.26)\end{array}$ & $\begin{array}{l}56 \\
(90.32)\end{array}$ & $\begin{array}{l}233 \\
(94.72)\end{array}$ & $\begin{array}{l}2 \text { df. }=6.16 \\
p=0.045^{*}\end{array}$ & $\mathrm{p}=0.026^{*}$ \\
\hline Q 3 & Correct $(\%)$ & $\begin{array}{l}47 \\
(50)\end{array}$ & $\begin{array}{l}38 \\
(44.71)\end{array}$ & $\begin{array}{l}25 \\
(47.17)\end{array}$ & $\begin{array}{l}110 \\
(47.41)\end{array}$ & $\begin{array}{l}2 \mathrm{df} .=0.503 \\
p=0.77\end{array}$ & $\mathrm{p}=0.78$ \\
\hline Q 4 & $\begin{array}{l}\text { Correct } \\
(\%)\end{array}$ & $\begin{array}{l}52 \\
(55.32)\end{array}$ & $\begin{array}{l}33 \\
(39.29)\end{array}$ & $\begin{array}{l}24 \\
(42.11)\end{array}$ & $\begin{array}{l}109 \\
(46.38)\end{array}$ & $\begin{array}{l}2 \mathrm{df}=5.139 \mathrm{p} \\
=0.07 *\end{array}$ & $\mathrm{p}=0.08^{*}$ \\
\hline Q 5 & Correct $(\%)$ & $\begin{array}{l}25 \\
(26.6)\end{array}$ & $\begin{array}{l}45 \\
(51.14)\end{array}$ & $\begin{array}{l}50 \\
(80.65)\end{array}$ & $\begin{array}{l}120 \\
(49.18)\end{array}$ & $\begin{array}{l}2 \mathrm{df}=43.877 \\
\mathrm{p}<0.001 * *\end{array}$ & $\mathrm{p}<0.0001 * *$ \\
\hline Q 6 & Correct (\%) & $\begin{array}{l}42 \\
(44.68)\end{array}$ & $\begin{array}{l}41 \\
(48.81)\end{array}$ & $\begin{array}{l}35 \\
(62.5)\end{array}$ & $\begin{array}{l}118 \\
(50.43)\end{array}$ & $\begin{array}{l}2 \mathrm{df}=4.597 \\
p=0.10\end{array}$ & $\mathrm{p}=0.11$ \\
\hline Q 7 & Correct (\%) & $\begin{array}{l}70 \\
(73.68)\end{array}$ & $\begin{array}{l}83 \\
(94.32)\end{array}$ & $\begin{array}{l}55 \\
(88.71)\end{array}$ & $\begin{array}{l}208 \\
(84.9)\end{array}$ & $\begin{array}{l}2 \mathrm{df}=16.11 \\
\mathrm{p}<0.001 * *\end{array}$ & $\mathrm{p}<0.0001 * *$ \\
\hline
\end{tabular}

$\mathrm{N}=$ number of participants; * significant; ** highly significant

Table 4: Response of medical students and doctors to question related to attitude and practices of pharmacovigilance.

\begin{tabular}{|c|c|c|c|c|c|}
\hline Q. No & Response & $6^{\text {th }}$ semester $\mathrm{N}=95$ & $8^{\text {th }}$ semester $\mathrm{N}=\mathbf{8 9}$ & Doctor $N=62$ & Total $N=246$ \\
\hline \multirow{6}{*}{ Q. 8} & Option a (\%) & $4(4.21)$ & $4(4.49)$ & $3(4.84)$ & $11(4.47)$ \\
\hline & Option b (\%) & $32(33.68)$ & $24(26.97)$ & $7(11.29)$ & $63(25.61)$ \\
\hline & Option c (\%) & $21(22.11)$ & $17(19.1)$ & $16(25.81)$ & $54(21.95)$ \\
\hline & Option d (\%) & $18(18.95)$ & $15(16.85)$ & $8(12.9)$ & $41(16.67)$ \\
\hline & Various Options (\%) & $20(21.05)$ & $24(26.97)$ & $21(33.87)$ & $65(26.42)$ \\
\hline & Not mentioned (\%) & $0(0)$ & $5(5.62)$ & $7(11.29)$ & $12(4.88)$ \\
\hline Q 9* & Correct $(\%)$ & $93(97.89)$ & $88(98.88)$ & $62(100)$ & $243(98.78)$ \\
\hline Q $10^{*}$ & Correct (\%) & $64(67.37)$ & $47(53.41)$ & $37(60.66)$ & $148(60.66)$ \\
\hline \multirow{4}{*}{ Q 11} & a $(\%)$ & $18(18.95)$ & $23(25.84)$ & $12(19.67)$ & $53(21.63)$ \\
\hline & $\mathrm{b}(\%)$ & $72(75.79)$ & $63(70.79)$ & $48(78.69)$ & $183(74.70)$ \\
\hline & c (\%) & $3(3.16)$ & $2(2.25)$ & $0(0)$ & $5(2.04)$ \\
\hline & $\mathrm{d}(\%)$ & $2(2.11)$ & $1(1.12)$ & $1(1.64)$ & $4(1.63)$ \\
\hline \multirow{2}{*}{ Q 12} & $\mathrm{a}(\%)$ & $92(96.84)$ & $86(96.63)$ & $62(100)$ & $240(97.56)$ \\
\hline & $\mathrm{b}(\%)$ & $3(3.16)$ & $3(3.37)$ & $0(0)$ & $6(2.44)$ \\
\hline \multirow{2}{*}{ Q 13} & $\mathrm{a}(\%)$ & $63(66.32)$ & $51(57.3)$ & $46(74.19)$ & $160(65.04)$ \\
\hline & $\mathrm{b}(\%)$ & $32(33.68)$ & $38(42.7)$ & $16(25.81)$ & $86(34.96)$ \\
\hline \multirow{2}{*}{ Q 14} & $\mathrm{a}(\%)$ & $10(10.53)$ & $16(18.18)$ & $11(17.74)$ & $37(15.1)$ \\
\hline & $\mathrm{b}(\%)$ & $85(89.47)$ & $72(81.82)$ & $51(82.26)$ & $208(84.90)$ \\
\hline \multirow{2}{*}{ Q 15} & $\mathrm{a}(\%)$ & $10(10.53)$ & $4(4.49)$ & $10(16.13)$ & $24(9.76)$ \\
\hline & $\mathrm{b}(\%)$ & 85 (89.47) & 85 (95.51) & $52(83.87)$ & $222(90.35)$ \\
\hline
\end{tabular}

$\mathrm{N}=$ number of participants; * Q. 9 and 10 are analyzed by the Pearson chi square and Fisher exact test; the results of both tests are not significant.

The gender distribution of study participants showed female preponderance of $48 \%$ in sixth-semester and $71 \%$ in eighth-semester medical students (Table 2).

Regarding knowledge based questions from Q1 -7 (Table $3), 68 \%$ of the participants know the correct definition of PV (medical doctors $90 \%$; $8^{\text {th }}$ semester $76 \%$ and $6^{\text {th }}$ semester students $46 \%$. Fifty-three percent of the participants responded incorrectly to the question of location of the international centre of ADR and $46 \%$ of the entrants did not know about the regulatory centre responsible for ADR monitoring in India. Of the $49 \%$ participants who responded to knowing about the ADR monitoring centre (AMC) in our institute, $81 \%$ doctors are aware about the presence of an AMC in our institute than the other two groups. It is interesting to note that $94 \%$ of $8^{\text {th }}$ semester students and $89 \%$ of doctors know that who should be reporting ADRs. 
Questions 8 through 15 are related to attitude and practice of medical students and doctors towards pharmacovigilance and adverse event reporting (Table 4). Question 8 was about the factors that discourage health care professionals from ADR reporting. It had multiple responses from the participants with $11 \%$ of medical doctors, $27 \%$ of eighth-semester and $34 \%$ of sixthsemester students suggesting that lack of time discourage them from reporting ADRs. Medical doctors 26\%, eighthsemester $20 \%$ and six-semester students $22 \%$ consider that it is difficult to decide whether ADR have occurred or not. Medical doctors 13\%, eighth-semester $17 \%$ and sixthsemester students $20 \%$ students do not have any idea of where and whom to report ADRs. Almost all the partakers (99\%) of the study believed it is necessary to report an ADR. Sixty-seven percent of $6^{\text {th }}$ semester students compared to $61 \%$ doctors and $53 \%$ of $8^{\text {th }}$ semesters think that reporting is a professional obligation for them respectively. ADR reporting should be compulsory according to $77 \%$ of doctors compared to $75 \%$ and $71 \%$ of $6^{\text {th }}$ semester and $8^{\text {th }}$ semester students respectively. A whopping $90 \%$ of the participants thought HCPs should receive education in PV. Doctors $74 \%$ have seen ADRs but only a meagre $16 \%$ of doctors have ever reported any suspected ADRs. Only $18 \%$ of doctors and $8^{\text {th }}$ semesters followed by $11 \%$ of $6^{\text {th }}$ semester students have ever been taught / trained on how to report an ADR.

\section{DISCUSSION}

Reporting of ADRs is an essential component of PV and is crucial to the safety surveillance of marketed medicinal products. Spontaneous ADR reporting system is a vital method for detecting new safety issues related to drugs. ADRs contribute significantly to morbidity and mortality in clinical practice with its associated economic consequences.

Under-reporting of ADRs is a global phenomenon and the ADR reporting situation in India is still in the stage of infancy. ${ }^{13}$ Amongst various factors, knowledge and attitudes of HCPs play a significant role in spontaneous reporting of ADRs. ${ }^{9}$ Hence, the present study was taken up to assess the KAP of PV among medical students and doctors to find out the reasons for under-reporting and also to create awareness about PV.

\section{Knowledge of pharmacovigilance}

Doctors know the basic definition of PV better than the students. This may be due to their vast experience in clinical practice and also because we had conducted a continuing medical education programme (CME) on this topic to encourage them to actively participate in reporting ADRs. The sixth-semester students had heard about the thalidomide disaster more than the rest which could be due to coverage of the topic in recent theory classes. $46 \%$ of participants' know about the international centre for ADRs and the regulatory body responsible for ADR reporting in India. This result shows that there is a need and scope for creating awareness among both medical students and doctors regarding pharmacovigilance programme of India (PvPI). Only 50\% of the participants know that rare ADRs are detected in phase 4 clinical trials (post-marketing surveillance). There is a need for regular training and reenforcement of these facts to medical doctors that rare adverse effects of drugs are not detected during the clinical phases I, II and III and reporting of any suspected, unexpected and unlisted adverse drug reaction becomes important. Understandably, doctors were more aware than students of the presence of an AMC in our institute as ADR reporting forms have been distributed to them in the past few years. The fact that eighth-semester students had better knowledge than doctors about who are the responsible individuals for reporting ADRs showed that more awareness about PV is needed for practicing doctors.

\section{Attitude and practices regarding pharmacovigilance}

In our study, $26 \%$ of participants consider that lack of time is the primary reason for not reporting ADRs, $22 \%$ of entrants have difficulty in diagnosing ADRs, $17 \%$ of participants do not know where and whom to report ADRs, $4 \%$ entrants are concerned about the legal aspects of reporting ADRs and $26 \%$ candidates believe that a combination of these above factors discourage them from reporting ADRs. Various other factors that discourage participants from ADR reporting include the belief that the ADR in question was already well known and common, the ADR is not serious and uncertainty concerning the causal relationship between the ADR and drug. Strategies to improve reporting of ADRs by including topics of PV in medical curriculum and educating them that any suspected ADRs are to be reported even if one is not sure about it. Other modalities to encourage HCPs to report ADRs include easy access to ADR forms, toll free numbers to contact AMC of the institution and CME activities to create the awareness about the building of Indian database of ADR and PV. These activities may reduce the barriers and misconceptions that discourage reporting of ADRs. All the three groups (sixth, eighthsemester students and doctors) felt that ADR reporting is necessary, and that PV should be taught in detail to HCPs. It reveals a positive attitude of the participants and this finding is almost similar to previous studies. ${ }^{14}$

A larger number of doctors had seen ADRs than the other two medical student groups. This is probably due to their long years of medical service and experience compared to students. Despite this, the practice of actual ADR reporting was below expectations because we observed from our study that only $16 \%$ of doctors followed by $11 \%$ and $4 \%$ of $6^{\text {th }}$ and $8^{\text {th }}$ semester students respectively have ever reported any suspected ADRs. A lack of knowledge of even recognizing an ADR or knowing where to report it were major hindrances in actual reporting when compared to the attitude. Several studies have shown that a lack of time and knowledge about ADRs is often considered to be the cause of underreporting of ADRs. ${ }^{15,16}$ Addressing these factors and clarifying the misunderstandings about ADR 
reporting may help in improving the conversion of attitude towards practice of reporting ADRs.

There is an enormous gap in the KAP of PV and ADR reporting awareness in our institution and it is also reported by several other studies conducted in different parts of the world. ${ }^{17,18}$ Thus, there is a need of education, awareness and hands on training about the reporting of ADR by HCPs. Our study has two important limitations. Firstly, the study has a limited number of medical doctors. Secondly, we did not include nurses, pharmacists and other HCPs. Therefore we recommend that similar such studies should be conducted among nurses, pharmacist and other HCPs so as to improve the KAP of PV in India.

In the present study, we found that while there is right attitude for ADR reporting among medical students and doctors, but the actual practice of ADR reporting was lacking particularly among doctors. Conducting CME on $\mathrm{PV}$ and giving training to prescribers about PV seems to be an immediate necessity. The training program should cover the all aspects of PvPI, including hands-on training of filling of ADR reporting form.

\section{CONCLUSION}

Poor reporting of ADRs, especially in India, is essentially due to the absence of a vibrant ADR monitoring system and also inadequacies in reporting culture among HCPs. The reporting rate of ADRs could be improved with proper and extensive training about PV in HCPs. We conclude that further large-scale awareness of PV is required among medical students, who are our future doctors, for better understanding and reporting of ADRs. Incorporation of PV in the medical curriculum and medical internship is required to bring awareness about the rational usage of drugs; thereby minimizing adverse drug events or other drug related problems.

\section{ACKNOWLEDGEMENTS}

The authors would like to thank Dr. K. Santhosh Kumar, Professor and Head, Department of Pharmacology, KAMSRC, Hyderabad and Dr. L Ramesh, Professor, Department of Pharmacology, KAMSRC, Hyderabad, for their valuable support and guidance throughout the study.

Funding: No funding sources Conflict of interest: None declared

Ethical approval: The study was approved by the Institutional Ethics Committee

\section{REFERENCES}

1. Abubakar AR, Chedi BA, Mohammed KG, Haque M. Perception of Nigerian medical students on adverse drug reaction reporting. J Adv Pharm Technol Res 2015;6:154-8.

2. Haile DB, Ayen WY, Tiwari P. Prevalence and assessment of factors contributing to adverse drug reactions in wards of a tertiary care hospital, India. Ethiop J Health Sci. 2013;23:39-48.

3. Hazell L, Shakir SA. Under-reporting of adverse drug reactions: a systematic review. Drug Saf. 2006;29:385-96.

4. Bouvy JC, De Bruin ML, Koopmanschap MA. Epidemiology of adverse drug reactions in Europe: a review of recent observational studies. Drug Saf. 2015;38:437-53.

5. Lazarou J, Pomeranz BH, Corey PN. Incidence of adverse drug reactions in hospitalized patients: a metaanalysis of prospective studies. JAMA. 1998;279:1200-5.

6. Wester K, Jonsson AK, Spigset O, Druid H, Hagg S. Incidence of fatal adverse drug reactions: a population based study. Br J Clin Pharmacol. 2008;65:573-9.

7. Smith CC, Bennett PM, Pearce HM, Harrison PI, Reynolds DJ, Aronson JK, et al. Adverse drug reactions in a hospital general medical unit meriting notification to the Committee on Safety of Medicines. Br J Clin Pharmacol. 1996;42:423-9.

8. Kalaiselvan V, Thota P, Singh GN. Pharmacovigilance Programme of India: Recent developments and future perspectives. Indian $\mathbf{J}$ Pharmacol. 2016;48:624-8.

9. Upadhyaya HB, Vora MB, Nagar JG, Patel PB. Knowledge, attitude and practices toward pharmacovigilance and adverse drug reactions in postgraduate students of Tertiary Care Hospital in Gujarat. J Adv Pharm Technol Res. 2015;6:29-34.

10. Ganesan S, Sandhiya S, Reddy KC, Subrahmanyam DK, Adithan C. The Impact of the Educational Intervention on Knowledge, Attitude, and Practice of Pharmacovigilance toward Adverse Drug Reactions Reporting among Health-care Professionals in a Tertiary Care Hospital in South India. J Nat Sci Biol Med. 2017;8:203-9.

11. Gupta SK, Nayak RP, Shivaranjani R, Vidyarthi SK. A questionnaire study on the knowledge, attitude, and the practice of pharmacovigilance among the healthcare professionals in a teaching hospital in South India. Perspect Clin Res. 2015;6:45-52.

12. Hardeep, Bajaj JK, Rakesh K. A survey on the knowledge, attitude and the practice of pharmacovigilance among the health care professionals in a teaching hospital in northern India. J Clin Diagn Res. 2013;7:97-9.

13. Tandon VR, Mahajan V, Khajuria V, Gillani Z. Under-reporting of adverse drug reactions: a challenge for pharmacovigilance in India. Indian J Pharmacol. 2015;47:65-71.

14. Chopra D, Wardhan N, Rehan HS. Knowledge, attitude and practices associated with adverse drug reaction reporting amongst doctors in a teaching hospital. Int J Risk Saf Med. 2011;23:227-32.

15. Lopez-Gonzalez E, Herdeiro MT, Figueiras A. Determinants of under-reporting of adverse drug reactions: a systematic review. Drug Saf. 2009;32:1931. 
16. Williams D, Feely J. Underreporting of adverse drug reactions: attitudes of Irish doctors. Ir J Med Sci. 1999;168:257-61.

17. Agarwal R, Daher AM, Mohd IN. Knowledge, practices and attitudes towards adverse drug reaction reporting by private practitioners from klang valley in malaysia. Malays J Med Sci. 2013;20:52-61.

18. Alshammari TM, Alamri KK, Ghawa YA, Alohali NF, Abualkol SA, Aljadhey HS. Knowledge and attitude of health-care professionals in hospitals towards pharmacovigilance in Saudi Arabia. Int J Clin Pharm. 2015;37:1104-10.

Cite this article as: Beedimani RS, Zaman SU, Darbha S, Potturi SC. An evaluation of knowledge, attitude and practice of pharmacovigilance among medical students and doctors at a tertiary care hospital. Int J Basic Clin Pharmacol 2018;7:324-32. 


\section{ANNEXURE}

\section{Questionnaire for pharmacovigilance:}

\section{(Do not write your name)}

Age: Sex:

Department:

Current position:

1. Final Year MBBS student ------- semester

2. Final Year MBBS student ------- semester

3. DNB resident

4. Consultant

5. If Others, Please Specify

1) Pharmacovigilance is

a) The science of studying clinical trials

b) The process of inspection of drugs

c) The detection and reporting of adverse effects

d) None of the above

2) Do you know about either 'Thalidomide Disaster'?

a) Yes

b) No

3) The international center for adverse drug reaction located in

a) Unites States of America

b) United Kingdom

c) India

d) Sweden

4) The regulatory body responsible for ADR monitoring in India is

a) Central Drugs Standard Control Organization (CDSCO)

b) All India Institute of Medical Sciences (AIIMS)

c) Drug Controller General of India

d) Medical Council of India (MCI)

5) Is there any adverse drug reactions (ADRs) reporting and monitoring system at your hospital? 

a) Yes
b) No

6) Rare ADRs can be identified in the following phase of a clinical trial

a) During phase- 1 clinical trials

b) During phase-2 clinical trials

c) During phase-3 clinical trials

d) During phase-4 clinical trials

7) Who are the healthcare professionals responsible for reporting ADRs in a hospital?
a) Doctors
b) Pharmacists
c) Nurses
d) All of the above

8) Which among the following factors discourage you from reporting Adverse Drug Reactions?

a) Legal Inquiry/Action involved for reporting an ADR

b) Lack of time to report ADR

c) Difficult to decide whether ADR has occurred or not

d) Not Know where and whom to report

e) Patient's confidentiality not to be disclosed

f) Non-remuneration for reporting

g) Socio-economic, cultural and religious beliefs involved

9) Do you think reporting of adverse drug reaction is necessary?
a) Yes
b) $\mathrm{No}$

10) Do you think reporting is a professional obligation for you?
a) Yes
b) No

11) ADR reporting should be
a) Voluntary
b) Compulsory
c) Remunerated 
d) No need to report

12) Do you think Pharmacovigilance should be taught in detail to healthcare professionals?
a) Yes
b) No

13) Have you ever seen an individual with an Adverse Drug Reaction?

a) Yes

b) No

14) Have you ever been trained on how to report Adverse Drug Reaction (ADR)?

a) Yes

b) No

15) Have you reported any suspected adverse drug reactions to any of the ADR reporting and monitoring centres?

a) Yes

b) No

Any suggestions: 